\title{
Copyright
}

by

Timothy Duane Schmidt

2011 
The Report committee for Timothy Duane Schmidt certifies That this is the approved version of the following report:

\section{Resonance and Resistance}

\section{APPROVED BY}

SUPERVISING COMMITTEE:

Supervisor:

Margo Sawyer

Teresa Hubbard 


\title{
Resonance and Resistance
}

by

Timothy Duane Schmidt, B.F.A

\author{
Report
}

Presented to the Faculty of the Graduate School

of the University of Texas at Austin

in Partial Fulfillment

of the Requirements

for the Degree of

Master of Fine Arts

The University of Texas at Austin

May 2011 


\section{Dedication}

To my family 


\title{
Abstract
}

Resonance and Resistance

\author{
Timothy Duane Schmidt, MFA \\ The University of Texas at Austin, 2011
}

Supervisor: Margo Sawyer

This Master's Thesis Report is a chronological investigation of the ideas and processes that I have researched and explored during the last three years at the University of Texas at Austin. This exploration has led to a body of work that examines material culture and the way that historical context affects the understanding of the objects and environments of our culture. 


\section{Table of Contents}

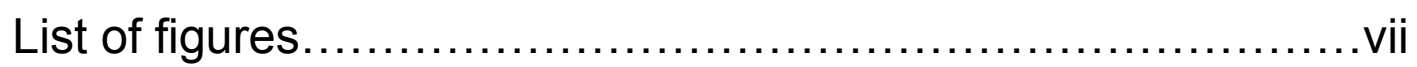

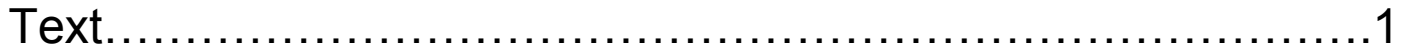

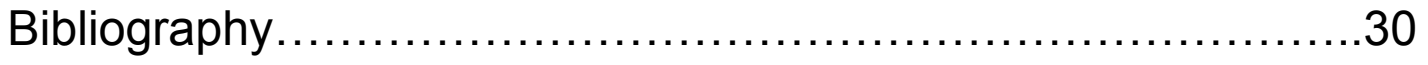




\section{List of Figures}

Figure 1: Wu Ping's House, China.Getty Images...............................2

Figure 2: Mixed Use, 48" x 72" x 42", 2008.................................

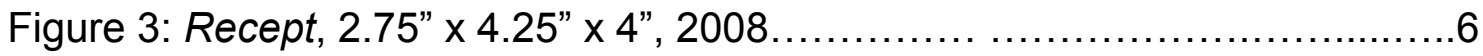

Figure 4: Object of Ambigificity (For Judd), 21.5” x 21.5” x 30", 2009............8

Figure 5: Installation View, 2009............ $\ldots \ldots \ldots \ldots \ldots \ldots \ldots \ldots \ldots \ldots \ldots \ldots$

Figure 6: Farewell Transmission, dimensions variable, with sound, 2009......13

Figure 7: The Birth of an Idea, 27" x 34", 2009..............................14

Figure 8: Excavated Book (floor) and Expansion of Space, 2009...............16

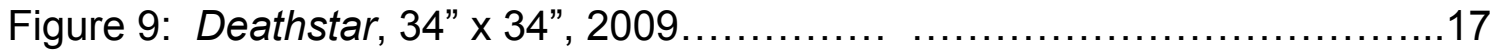

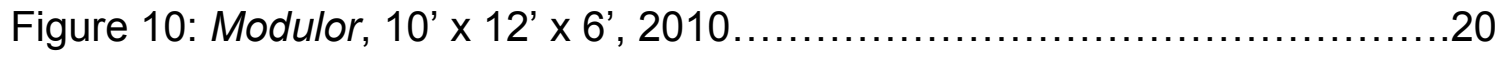

Figure 11: Historic Façade, 74" x 92" x 52", 2010.............................24

Figure 12: Exploded Floor, 45" x 85" x 13", 2011 .............................25

Figure 13: Exploded Floor II, 108" x 99" x 18", 2011 ...........................26

Figure 14: The Circular Ruins, dimensions variable, with sound, $2011 \ldots \ldots \ldots \ldots .28$ 


\section{Resonance and Resistance}

"For what had happened many centuries before was repeating itself." -Borges, "The Circular Ruins"1

In 2007, a Chinese woman named Wu Ping refused all offers for her restaurant and house from a real estate developer that had plans to develop the area into a shopping center. Although the developer went ahead with the groundbreaking and excavation of the site around her house, Wu Ping's continued protest became increasingly emphatic as the ground around her house was removed, raising her house higher and higher above the surrounding property as a monument to the cause of millions of people in China and around the world that have been relocated in the wake of cataclysmic development and urbanization. To the developers, Wu Ping's house is known as a 'stubborn nail' (figure 1). The photographs of Wu Ping's house suggest something different, that this simple house resonates as a monument to conflicting forces and ideals as well and exposes the systems in which the structure exists, both physically and politically.

\footnotetext{
${ }^{1}$ Borges, Jorge Luis, "The Circular Ruins", translated by Anthony Bonner. From Ficciones, Grove Press. 1962. p 63
} 


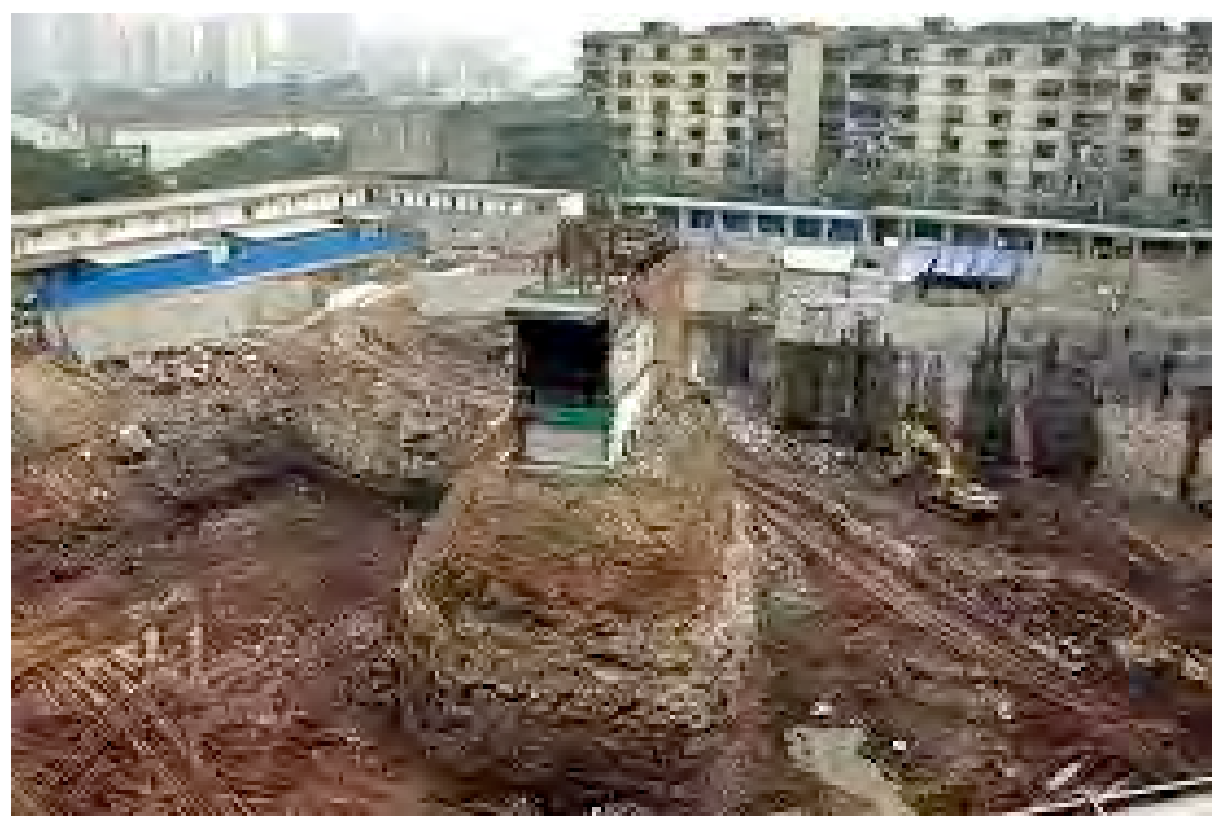

Figure 1. Wu Ping's House, China, Getty images

My interest in objects exists in the systems embodied by that object. No thing exists statically. All of the material culture that we perceive to be permanent fixtures of our environment is, in one way or another, changing. We build things to stabilize our daily experience and to produce an existence of routines, in which our environment is the same today as it was yesterday. We take for granted the permanence of the buildings around us and we fail to recognize what ideas and problem solving led to the construction of each structure and object. Once created, we see these buildings and objects as finished and static representations of our values, but all things face the forces of nature, social change, political shifts, history and entropy, which gives these things a more powerful resonance in the eye of the viewer or inhabitant. Often when we are cycling through our routines is when we are least able to recognize the profound 
level at which our environments and the objects that we navigate resonate, because our experience of these things is so commonplace.

The work of Gordon Matta-Clark exemplifies an attempt to reintroduce the viewer to a familiar place from a new perspective. By making predetermined geometric cuts and dissections on architecture, Matta-Clark exposed the systems that are constantly working against external forces to keep a structure intact. In conjunction with the architectural interventions, Matta-Clark would also present the dissected building parts in a gallery with photographs and drawings.

(Matta-Clark) worked to suggest that apparently stable disciplines like architecture actually enjoyed multiple and conflicting ingredients. Crucially, he showed these conflicts could be productive, rather than being contradictory or destructive. His best work inscribed such productive conflict in the projects themselves, establishing an enduring invitation for questioning rather than providing set answers... 2

By exposing the systems involved in creating a structure, Matta-Clark shows the viewer the action of being a building and the forces that structures must overcome.

\footnotetext{
${ }^{2}$ Walker, Steven, Gordon Matta-Clark: Art, Architecture and the Attack on Modernism, I.B.Taurus, London, 2009, p.17
} 
He reinforces the idea of the building embodying an action by placing the pieces of the buildings into gallery spaces, which, during the post-Minimalism years, often played the role of a laboratory or a microscope. Whereas Minimalism produced objects that presented the viewer with a formal answer, Matta-Clark refused formal explanations in search of the questions associated with things.

In thinking about my own work, I am interested in the philosophical aims proposed by Matta-Clark. My own work deals with systems; both physical systems and ideological systems that exist within architecture. I am also influenced by the resonance that exists within objects through their own impermanence as well as their relationship to time and space. Whereas MattaClark performs interventions on public space and presents the documentation in the gallery, I recreate objects that I have seen and researched to expose the resonant qualities in the gallery. As in Matta-Clark's houses and in Wu Ping's house, there is an explicit action taken which activates the object in history.

\section{Site v. Specificity}

By the time I entered graduate school, I had developed a practice that involved making architectural models that revealed or criticized certain social values. I used architectural models as a way to question the prevailing political systems involved in civic design. Using the objects of infrastructure, in Mixed Use, 2008 (figure 2), I fabricated a scale model of a blank billboard and a similar scale fence that resembled either an interstate sound barrier or a border fence. Each of these 
objects was placed on a separate but identical portion of landscape that also served as pedestals for the objects. The act of celebrating them was also an act of subverting them. By being positioned on the same site and displayed in a similar way to an architectural proposal, they suggest a place that could just as easily lure one with an advertisement as it could keep someone from entering. The objects represent a conflict of ideals or the plurality of ideals in a society.

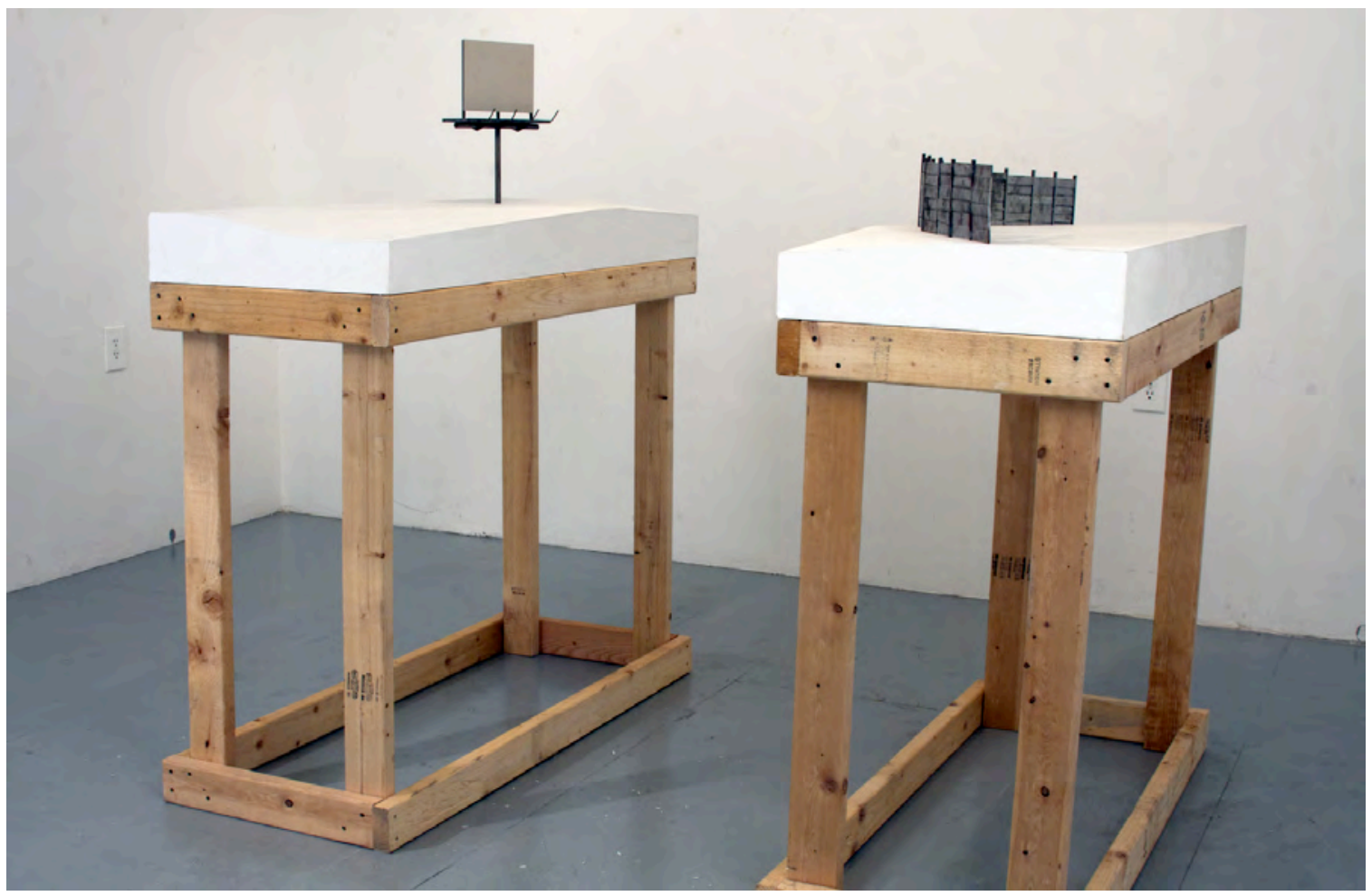

Figure 2. Mixed Use, 2008

The site (civic space) becomes schizophrenic. In a post-modernist (or postmodernist) world, the piece presents the lack of ability for site specificity. The 
site is everywhere and nowhere. The objects that inhabit the site are equally nonspecific.

I became aware of the ability for an artwork to flip flop between a social reading and an art historical reading. The objects on the landscape are stand-ins for the tropes of minimalism and site specificity. By subverting the politics of real world situations, the piece somehow also introduced an art historical context into my work. The piece, recept, 2009 (figure 5), was also made during this time in which I cast a standard electrical outlet in bronze. The lost wax-into- bronze casting process gave the outlet an art historical pedigree, while the installation of the object into the gallery wall to mimic the placement of the other outlets activated the gallery walls by creating a moment of detail in the imposter outlet. The object forces the viewer to look at the other outlets and fixtures in the space and wonder about their functionality. 'Are the light switches sculptures, too? Do they function? What is their function?' 


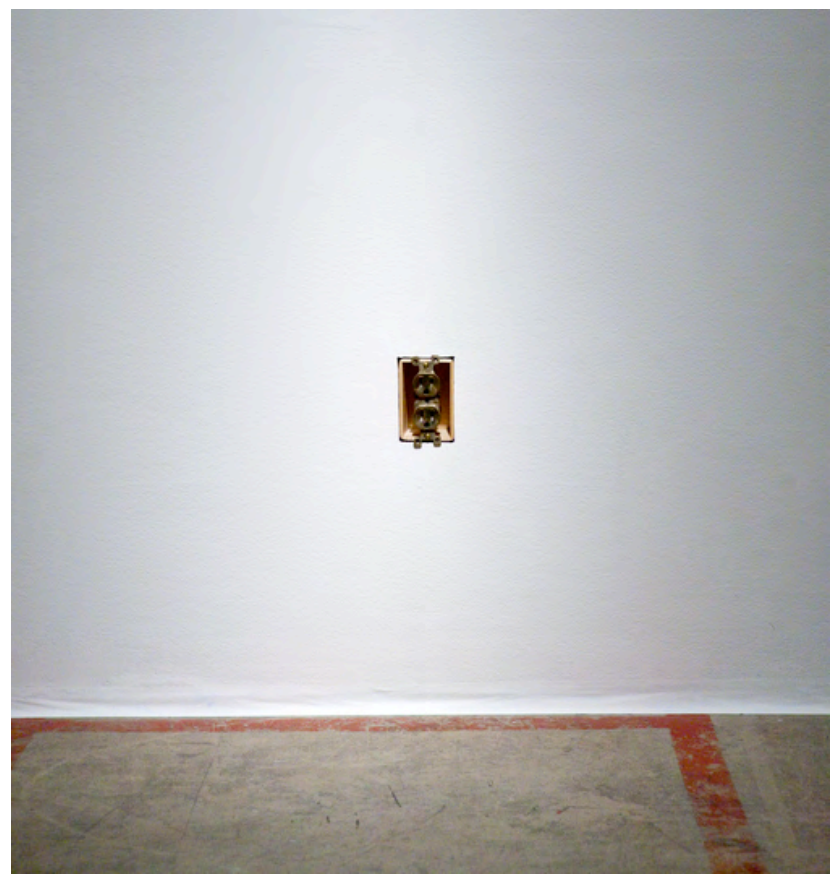

Figure 3: Recept, 2009

References to minimalism, site specificity, and modern architecture became evident in my thoughts and sculptures throughout the first year of graduate school. I am attracted to the aesthetic and philosophical aims of both minimalism and modernist architecture yet remain critical of the 'dogma' ascribed to these movements. In the piece Object of Ambigificity (for Judd), 2009 (figure 3), I constructed a form based on a chair designed by Donald Judd. Donald Judd's work expanded beyond making rational art objects and often overflowed into architecture and design. Given his diverse practice, and his political nature, I ventured to question, 'What would a Judd-designed world look like?' I approached this question by looking at Judd's furniture as architectural models and by imagining how they would look if they were under construction. The 
process in which a structure of a large civic building is made involves casting the beams and columns of the lower floors and moving the forms up and casting the structure of one floor at a time. Object of Ambigificity follows this method of construction where the lower section of the

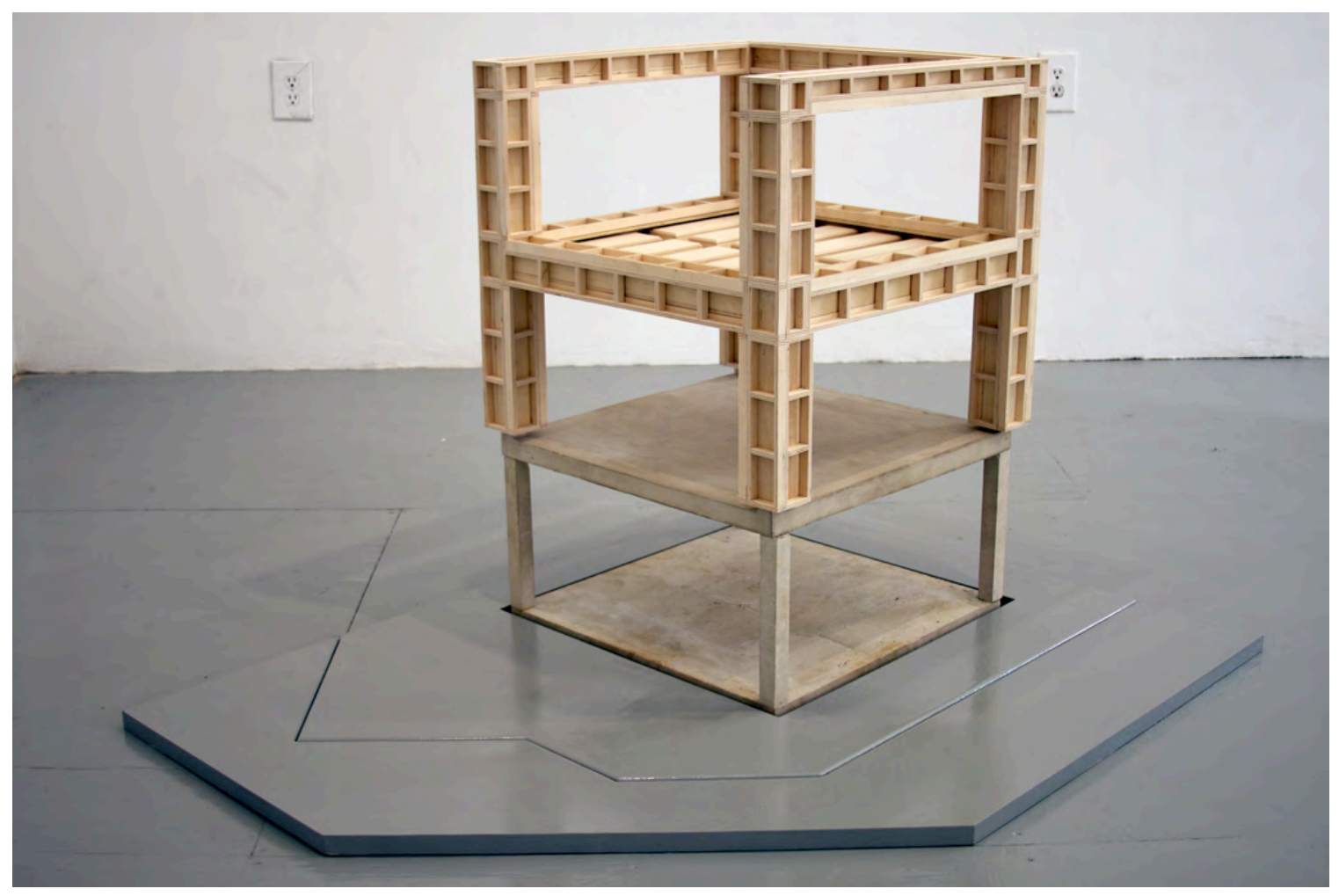

Figure 4. Object of Ambigificity (for Judd), 2009

chair is cast in concrete, while the upper half remains the wooden form. As an architectural model, the sculpture transforms Donald Judd's chair design into a generic type of building that could be a parking garage or apartments or a bank. There are few details to give the structure an identity. It is the type of building that no one will notice, let alone applaud. It is the type of building that fills in the multi- 
lane blocks of every urbanscape. This chair is not a specific object at all; it has become a generic object, which has a narrative and a history. As the viewer looks at this piece, it also jumps from one scale to another. The chair scale is very important and recognizable to the viewer, but the material forces the viewer to see the piece as an edifice. Adding to this narrative, I created a model-scale construction site that appeared to be excavated from the floor of the installation space to create an environment in which the chair was part of a developing business park that repeated the same building over and over (figure 4). The addition of the excavation site also implies another possible reading by suggesting a site-specific object must be rooted in its place. Site-specific themes also resonate among certain modern architects such as Frank Lloyd Wright, who is well known for his stubborn insistence that his furniture is specific to his home designs and must not under any circumstances be removed or redecorated.

These sculptures were the first installations that I made. I became interested in how the excavation site and Recept broke the plane of the floor and wall, respectively to activate the entire space. Opposed to the rational form as function inherent to minimalism, an electrical outlet's form only makes sense when one sees the form of an 


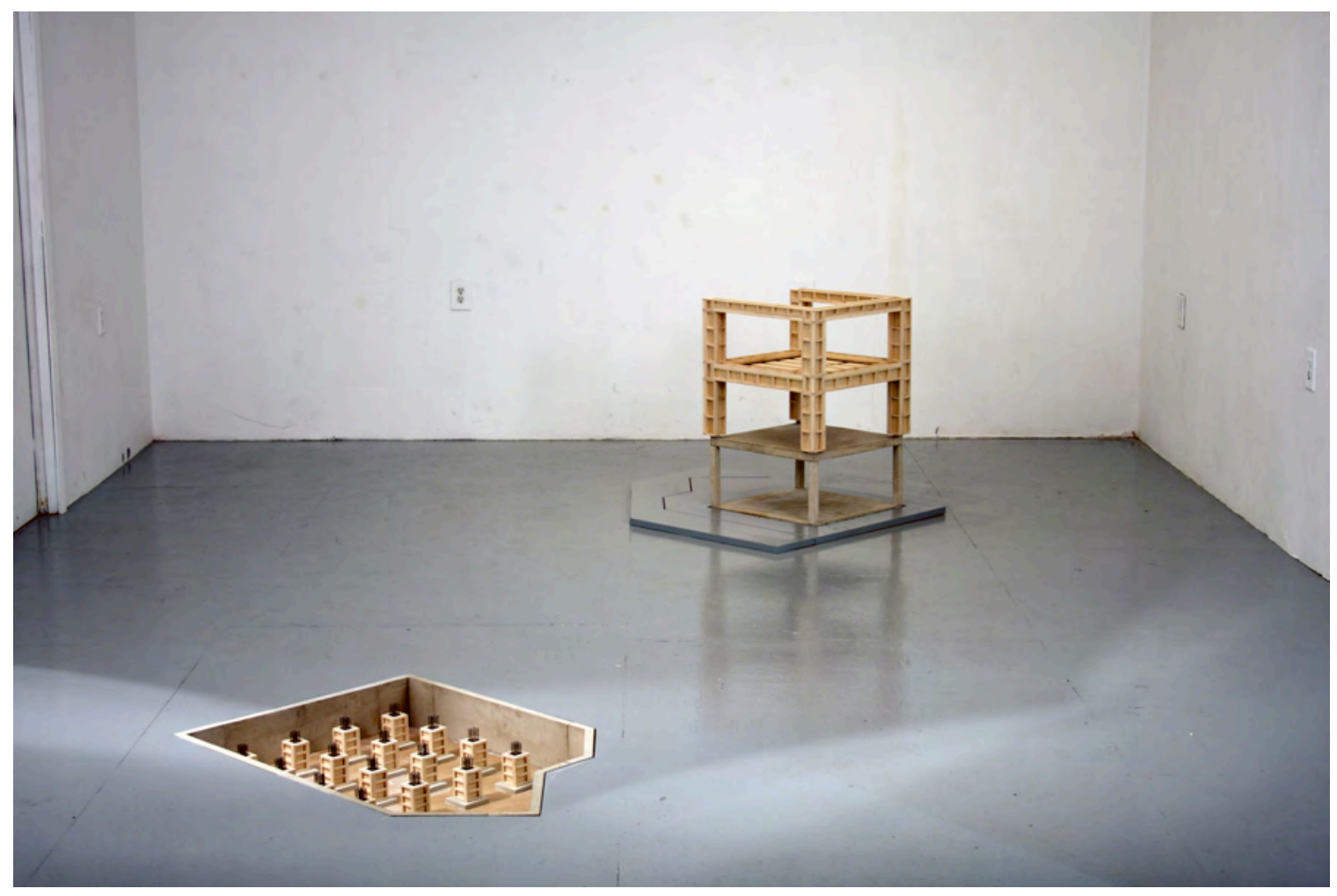

Figure 5: Installation view, 2009

electric plug, the opposite form that creates a perfect sexual union. But the actual function of the outlet disappears behind the paint, drywall and sheathing of the gallery wall, and into the web of wires that is fed by some kind of fire or raging stream of water somewhere else. It is Kubrick's black cube in 2001: A Space Odyssey. This process of qualifying objects by expanding their context is, I believe, in direct relation to the process in which the art gallery or museum focuses the perspective on an object to create resonance. 


\section{Classicism and Modernism v. The Future}

During my third semester, I created a body of work dealing with Classical architectural forms. Since Classical design encompasses a vast amount of our political and civic architecture from Washington D.C. to small county seats all across the United States, I was interested in its role as the embodiment of a system of ideals. Very obviously and basically, our political architecture attempts to project the democratic values that we as a culture inherited from the Greek and Roman civilizations. The buildings not only root our basic ideals in a historic tradition from which our beliefs evolved, but our contemporary architecture and the architecture of the future will have evolved from a point that began with the earliest understanding of engineering and passed through the Greek temples and through the Italian renaissance.

Looking at the political values of architecture and materials, I worked on a project that began from my daily encounters with the University football stadium. The stadium is easily the most prominent structure on campus and is itself an expression of the important place that football holds in the surrounding culture. The stadium is built like a fortress, with towers resembling watchtowers looking over each corner of the building. I became interested in the connection between classical architecture and the forms of the present and the idyllic future. The stadium as a site and form resonates throughout history. The amphitheater at Pompeii is one of the earliest preserved examples of stadium architecture that 
was actually built into the ground as the material to build the structure was being excavated. Besides being a civic center, this amphitheater is also a quarry. The site has been excavated as it was built. I also began thinking about stadiums as acoustic devices, speakers, in their form and function.

In my studio, I built a model of one of the towers out of common building materials that was about eight feet tall, large enough to retain the towering feel, but still a scale the viewer can fully engage with. Some windows were installed, through which some stereo equipment was visible and a yellow light glowed. In the vain of its authoritative stance, the tower became a type of control center. The tower stood on two wheels, which gave the structure a sense of movement, but which also caused the tower to tilt one way or the other. As opposed to the original tower, which is erect, rigid, and dominating, this re-creation has an instable foundation, and given its cylindrical shape and its lean, looks refers to classicism by resembling the leaning tower of Pisa. The tilt and technological interior of the tower placed the Classical structure into the potential future as a space traveling structure.

During this same time period, I saw an exhibition of Matthew Day Jackson's show, The Immeasurable Distance, 2009, which had an impact on me. Jackson created an installation that contained works dealing with numerous historic events that would seemingly relate to each other. It seemed as if he was working intuitively from material that he had relentlessly researched and was presenting a paraphrased version of American history told from his own personal storybook 
that contained art history, natural history, American history, and his imagination. His work also held together tightly in that he used many materials, techniques and scales to present a story that required the viewer to connect the dots.

I cast the form of a stadium in a concrete-like material, which I then supported with a scaffold structure that copied the triangulated structure invented by the visionary theorist and architect Buckminster Fuller. A speaker at the center of the stadium vibrates, creating patterns in concrete dust, which was poured into the speaker. The wires tether the stadium to the leaning tower where the amplifier is located to create a feedback loop. The control panel and glowing

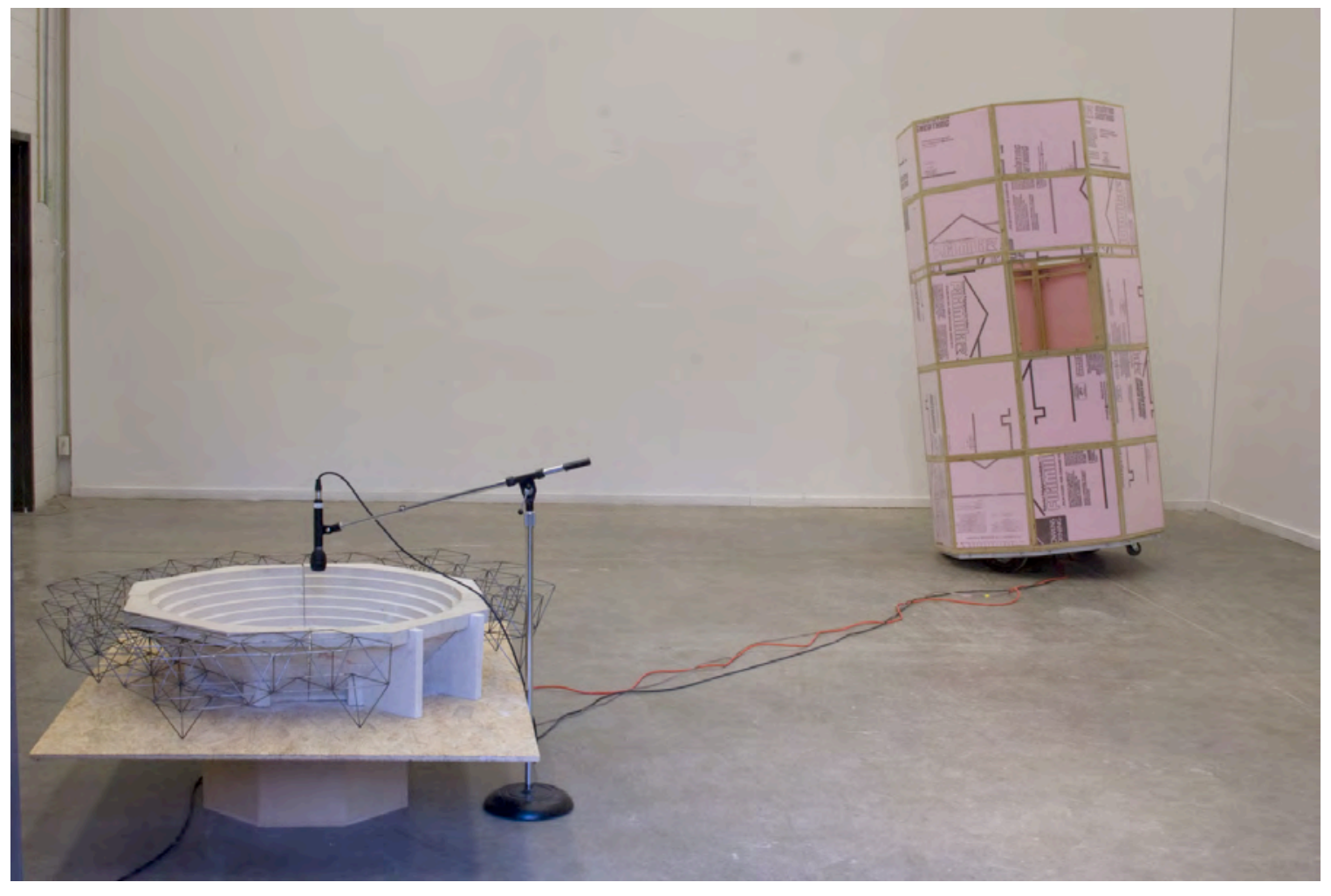

Figure 6: Farewell Transmission, 2009 
yellow light within the leaning structure give it the possibility of having a new purpose that, while rooted in historical form, suggests the cabin of an exploratory vehicle that isn't leaning because gravity and faulty engineering is pulling it down, it may actually be floating in space. Likewise, the tetrahedron scaffolding underneath the stadium also refers to a repurposed future in which the original heavy stone supports are replaced with a lightweight space age structure. (figure 6)

Tying to the idea of the stadium as a quarry, I am influenced by the quarries in the area that I am from. There is one quarry in particular known as Empire Quarry, where only the limestone used to clad the Empire State Building was mined. This quarry is a squarish cut that is very wide and deep and mostly filled with water. In my imagination, the Empire State building would fit perfectly upside down in that hole. These quarries are also the source for the material for many government buildings in the United States. In the piece hanging on the wall behind the stadium sculpture further directs the viewer to consider the importance of the material from which things are built. The image in this piece depicts the Texas state capital encased upside down within a monolithic block. The neoclassical design of the capital building is another reference to antiquity. A scaffold is supporting the dome. The red granite that the capital is built from is a material that has a lot of conceptual weight. (Figure 7) 


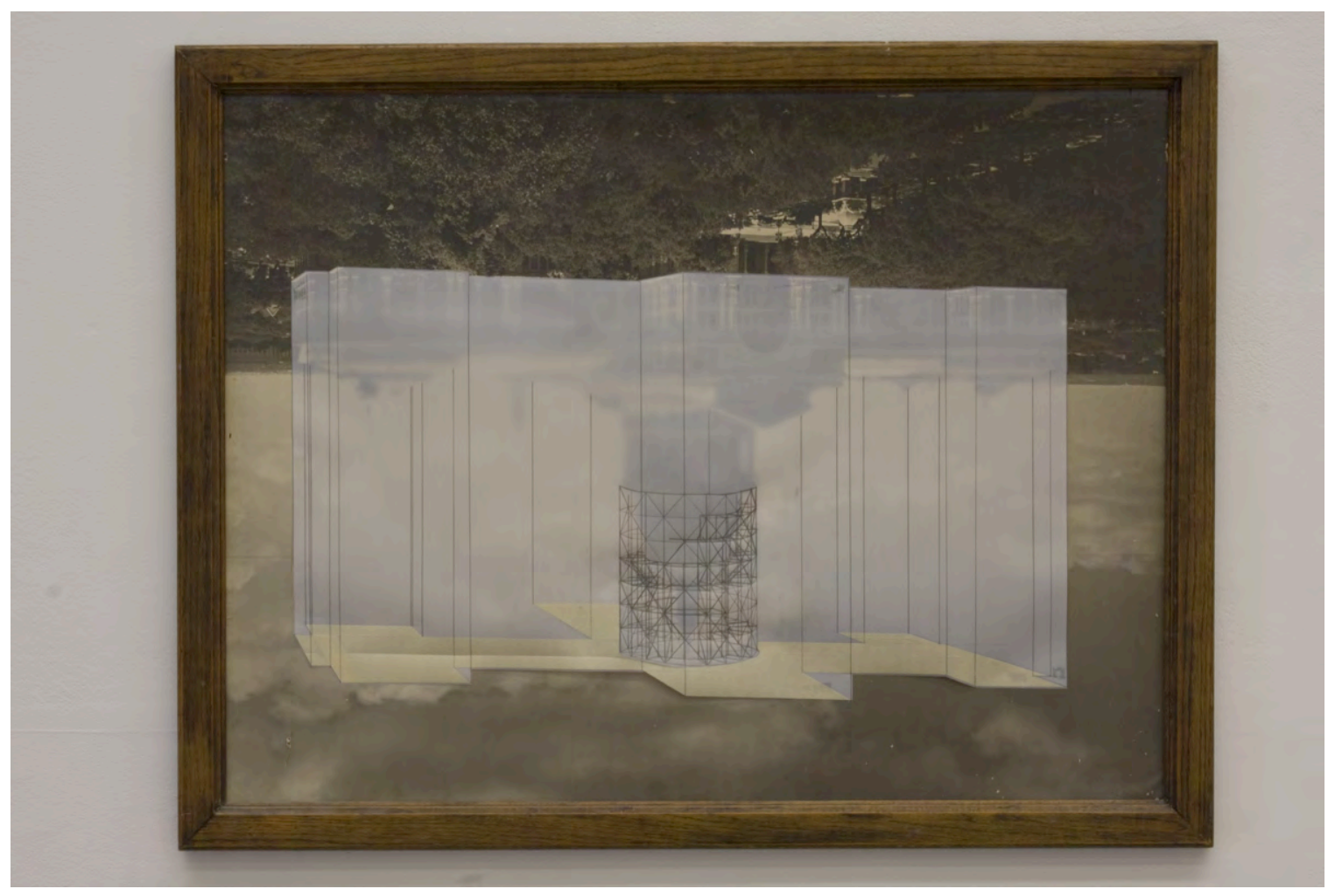

Figure 7: The birth of an idea, 2009

Another piece I made at this time relating to the quarries was a set of drawings I made using floor plans from a catalog I bought at home depot. Treating the floor plans like raw materials, I removed every floor plan from the catalog to create a hole through the book. Being a citizen of America during the last housing boom and the subsequent crash, led me to imagine the inhabiting of outer space using the same suburban floor plans we have now. (Figures 8 and 9) The system that these three pieces create is one in which each piece informed and was informed by the others. Each sculpture is a complete thought yet together, they create several chapters of information. Several avenues of thought could converge and diverge between the three objects. The most jarring aspect 
of the installation was the incessant sound of the feedback loop. The noise felt and sounded like an omnipresent element that filled every corner, nook and cranny of the installation space to the point of being repulsive. Despite the sound, viewers would inch close to the stadium that housed the speaker and as they lean in to view the piece can see the powder on the speaker creating vibrant patterns that keep the viewers eyes pulled into the center of the stadium.

The sound of the feedback loop introduced an aggressive quality that I felt like my work had been missing. Up to this point I felt that the pieces had a clever formula that linked a social commentary with a well-crafted form. Sound and light became materials that pushed and pulled with the objects to have a direct effect on the viewer. I became interested in pushing the viewer away with sound, while choosing to make moves that would keep the viewer looking. The way the speaker moved the dust in the stadium became a point of focus for my work. I could now see how materials are vulnerable to myriad forces, just as ideologies are vulnerable to conflicting ideologies. Sound also fulfilled the requirements of that installation. I decided that if I make an installation, I wanted it to be a full experience, not just visual. 


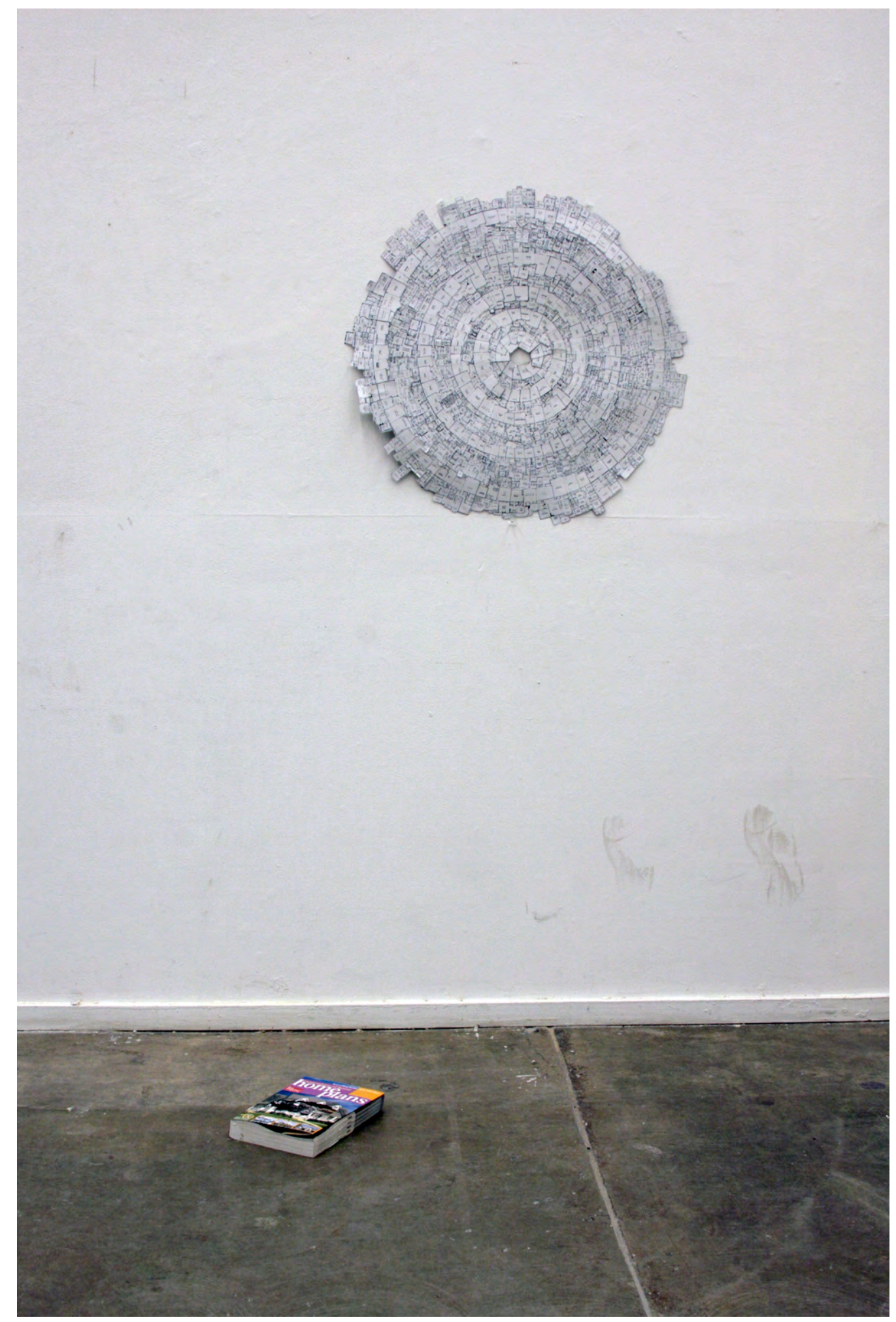

Figure 8: Excavated Book and Expansion of Space, 2009 


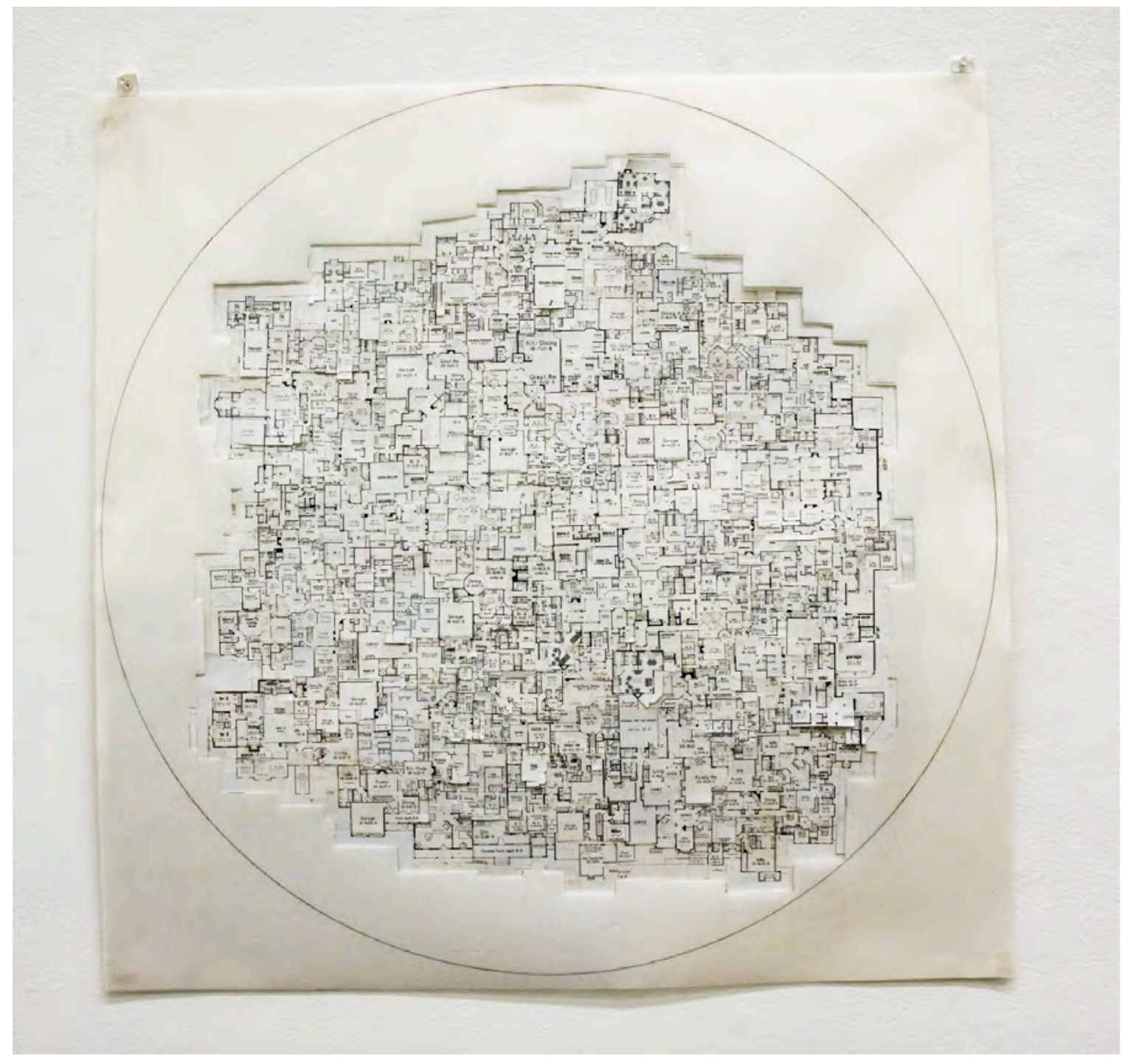

Figure 9: Deathstar

\section{Architecture v. Sound}

At this point in my career at UT, I had become interested in making larger and larger installations. Rather than building models that represented ideas, I 
sought to create actual interactions with structures to develop my ideas. The working area, that UT provided as part of my curriculum had a lot of physical and spatial limitations for the projects that I was interested in pursuing, so a sculptor friend and I rented a 2000 square foot space in east Austin that had been an auto repair shop, and converted it into a studio and white-walled gallery space. We spent many weeks during the semester of spring 2010 building walls, hanging drywall, installing lights and outlets, painting, installing windows, building storage and cleaning out the decades of collected refuse and debris from the warehouse. In April of 2010, we had the inaugural opening of the space. During that same time period, I was taking a course on the roots of modern architecture and design in the United States and was also thinking more and more about the utopian vision embodied by the International Style of the 20s and 30s and theorists such as Buckminster Fuller. These architects rationalized civil design and created a philosophy that architecture is machine that could create unified social order.

Having a large studio within the larger art community in Austin gave me both physical and cognitive space to produce artwork. For the first public opening of the space I used one of the large overhead doors of the studio as an opportunity to create a piece that existed both within a gallery environment and out into the public environment. With the large door raised open, I built a framed wall in which I constructed a large protrusion to the outside that tapered from seven feet square to 20 inches square. The protrusion stuck out of the building horizontally. At the narrow end of this horn shaped growth, I installed a subwoofer and I lined 
the interior of the structure with plywood painted white. From the inside of the space, this protrusion was a deep hole that sank back from the plane of the gallery wall. On a pedestal next to this hole was a small television monitor that broadcast a video of Le Corbusier giving a lecture, which I found on YouTube. I routed the audio from this video through the subwoofer at the back of the hole and the illegible noise boomed through the space, which caused the corrugated metal siding and roofing on the building to rattle. (Figure 10)

In "Towards a New Architecture", Le Corbusier presents a manifesto for a new type of architecture. First published in Europe in 1923, the American industrial revolution was in full swing. Airplanes, automobiles and all types of other gadgets were changing the human experience. Le Corbusier was determined to build a 'machine for living in'. The primary influences for his architectural designs were the industrial buildings that were being produced in the United States to store grain and to house the new factories. Although the studio building in which I made this protrusion was of a later era, after reading Le Corbusier's emphatic prose, it seemed appropriate to 'shake' some life into the building with Corbu's voice, which was as hard to understand as the teacher's voice on the Charlie Brown cartoons. The form of the structure did not, itself, refer to any particular history in art or architecture. I was merely interested in the structure affecting both the inside of given the booming audio coming from the 
piece, the depiction of Le Corbusier on the small tv seemed very undersized, as

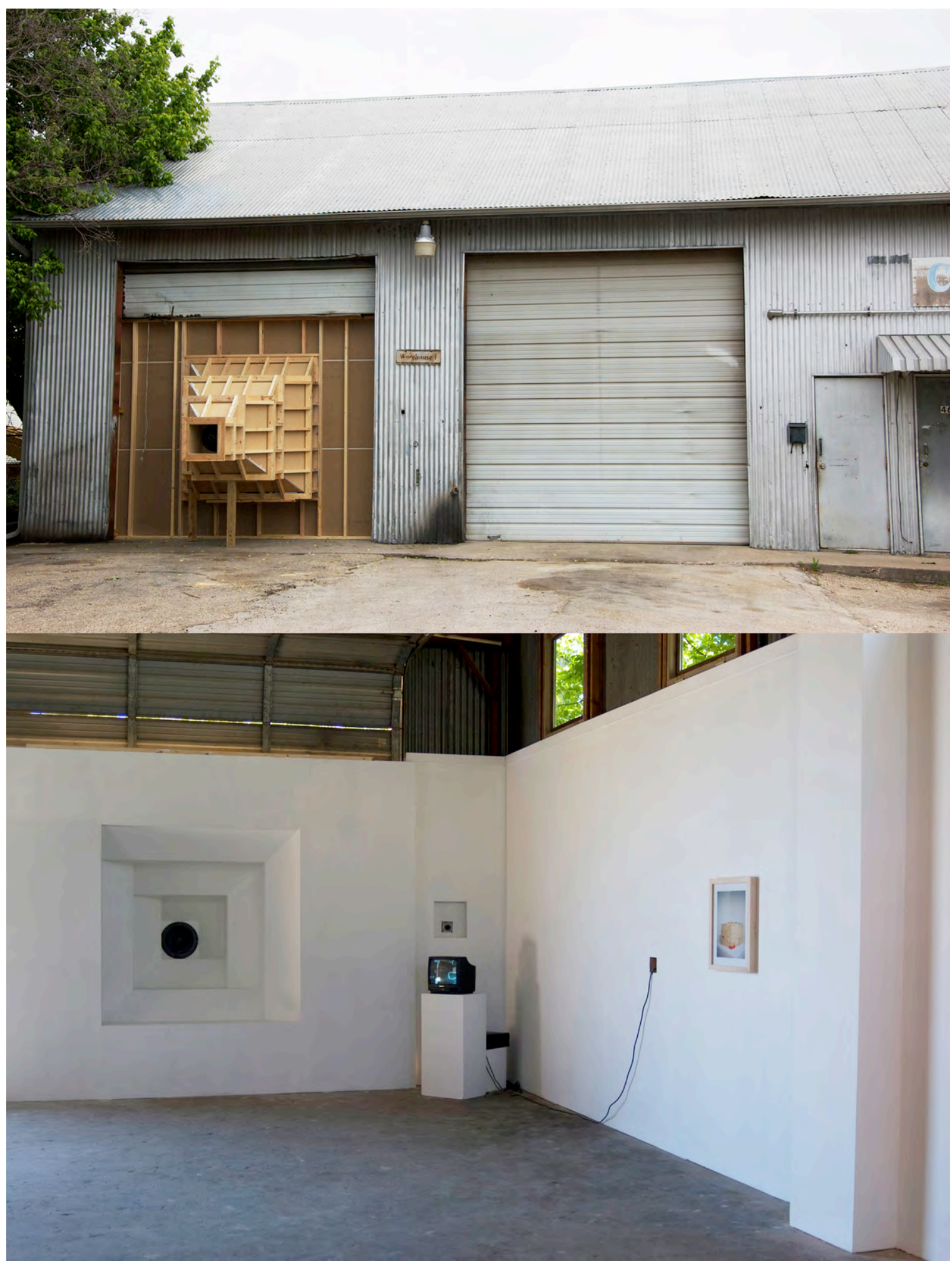




\section{Figure 10: Modulor, 2010 (exterior and interior views)}

if he were the wizard behind the curtain, not nearly as powerful as his voice or writing would suggest. the gallery and the outside of the warehouse.

The presence of sound and vibration in my work acts as a force within or upon the architecture. By suggesting and projecting the presence of sound in the pieces, through the use of speaker forms and graphic designs associated with a sound, I am suggesting an event or force taking place on the objects. Similar to the way that many of the objects that I recreate represent political structures, the sound that I impose or incorporate into the pieces also represents a political resistance. Like the subcultures within our society that challenge the stasis of the political structure, I am suggesting collisions of ideals, struggles for power and equality, and transformative events in the history of the objects. Music culture has a history of questioning the prevailing notions of power and social norms. The philosophy of events such as rock shows also embody a type of utopian idealism that is a bit more anarchic, perhaps than the structured idealism of architects and designers. The architecture of the rock show embodies a vibrant 'anything could happen here' energy. Sound in itself is an energetic vibration that fills the void of space and is a physical force that can manipulate all other materials.

Having used concrete in many of my previous pieces, I became more and more aware of its connotations as a building material and what its purpose was in my own work. Besides having the characteristic of assuming any form and 
having a broad range of possible textures, concrete represents, to me, a human attempt at controlling not only the wilderness of the environment and unpredictability of climate, but also the wildness of human existence. Concrete is also a material, like stone, but not as ceremonial as stone, that immortalizes every moment of our society. However, concrete doesn't just function as a monument, it is also the most prevalent material we encounter. It must exist in the form of dust, liquid, solid, and eventually will return to dust throughout its existence. When concrete is poured, it, like sound, fills every void in its reach, but where sound vibrates all that it encounters; concrete restricts all that it encounters. In direct contrast to sound waves, concrete is dense, rigid, deadening and repellent. Sound easily bounces off concrete, but can be contained by it.

It is these contrasting qualities that led me to begin experimenting with sound's qualities as a material and its effect on other materials. There are numerous video examples on the Internet of how different frequencies of sound can manipulate salt or other particulate matter to arrange in different physical patterns. These patterns are symmetrical and well defined and each pattern relates to a particular frequency. I wondered if such a pattern could be recorded in concrete. Although I never successfully recorded a visual record of sound in a material, I ran many experiments in which I would pour plaster onto a vibrating speaker and video the patterns as the plaster set. It turns out that the slow transition from liquid to solid gives gravity a chance to level the plaster out before 
the pattern solidifies. I am still very interested in trying new materials that have the potential to record this process.

I am also interested in the phenomenon of sound having the ability to weaken and break materials. I am mostly interested in these tests as a conceptual activity, not as an attempt to patent a new weapon. I am sure many far more technical and successful experiments have been executed in this area of research; however, my interests rely on my studio practice and the acquisition of knowledge or understanding through personal curiosity and artistic practice.

To contain the idea of sound in form, I made rubber molds of a guitar amp and cast the amps in concrete. The pieces are a representation of sound and of youthful rebellion, except that the concrete deadens the function of the amp, and turns it into a monument, as if that dynamism of its former self is now only a memory. The density of the concrete accentuates the amplifier's stillness, but the form of the amp still embodies the expression of sound through the shape of the deep woofer and the detailed control knobs on the panel. I then began building speaker boxes to make molds of in order to create my own concrete building blocks that had the form of speakers. With these large modular objects, I built a wall. This piece, Historic Façade (figure 11), took an idea regarding a current practice of downtown revitalization in which a building is demolished, but its façade is saved as a quaint relic of a city's character, and applied that idea to the architecture of a rock show. The speakers that I cast have the style of speakers from the 1970s, which is the 'historic' time period that the piece is referring to. 
Several bands from that time period began experimenting with stage sets that included huge stacks and walls of speakers. I was interested in creating a monument to a former time in American history, one in which political power was being challenged by an idealist vision. The rock shows of the Sixties and Seventies have, in several cases, become mythological; from the Beatles on Ed Sullivan to the Hendrix at Woodstock to the Stones at Altamont. The latter of these presents us with the equivalent of the end times of the myth. The utopian vision of the American counterculture that had reached full swing during the

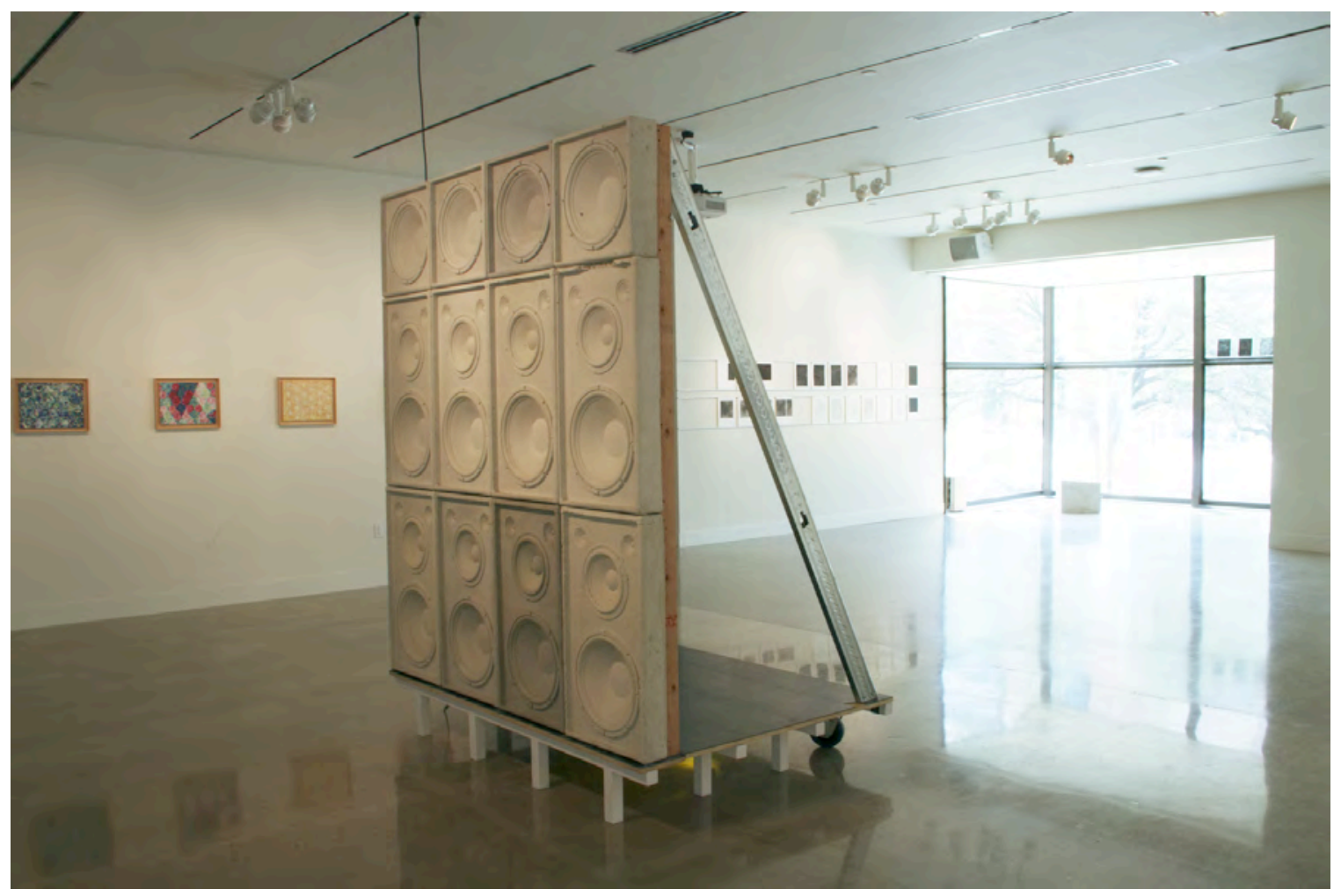

Figure 11: Historic Facade, 2011 
Summer of Love and had made the pilgrimage to Woodstock and returned proud of the peace and love that had been accomplished. The Altamont Free Concert shattered all of those utopian visions when the Hell's Angels incited violence and left one concertgoer dead. ${ }^{3}$ As with earlier pieces, such as the Donald Judd chair, my process began with turning an object into architecture. I was interested in the architecture of a rock show as a utopian expression of the world. However, being concrete, the speakers in the sculpture are noticeably silent; their vitality has been quelled. The only hope remaining in the piece is the glowing of the black lights that brace the façade up as we wait for what will be built next. Interested in the idea of alluding to the destruction of a structure within a piece, I began making floor structures on which I inlayed different color vinyl tiles in the shape of a graphic explosion such as those prevalent in graphic novels or the work of Roy Lichtenstein on which would be written 'BOOM!!!!' This gesture was intended to be a visual representation of sound, contained within the flooring material. I then propped these floor sections up vertically. (Figures 12 and 13) I was interested in the explosion existing above the ground but still happening to the floor, or as an aerial view of a massive detonation. As I made these pieces, I

\footnotetext{
${ }^{3}$ For a less 'mythological' version of the concert at Altamont read Coates, Norma, "If Anything Blame Woodstock" in Performance and Popular Music, Edited by Ian Inglis. Ashgate, Hampshire, England. 2006. P.58-69
} 


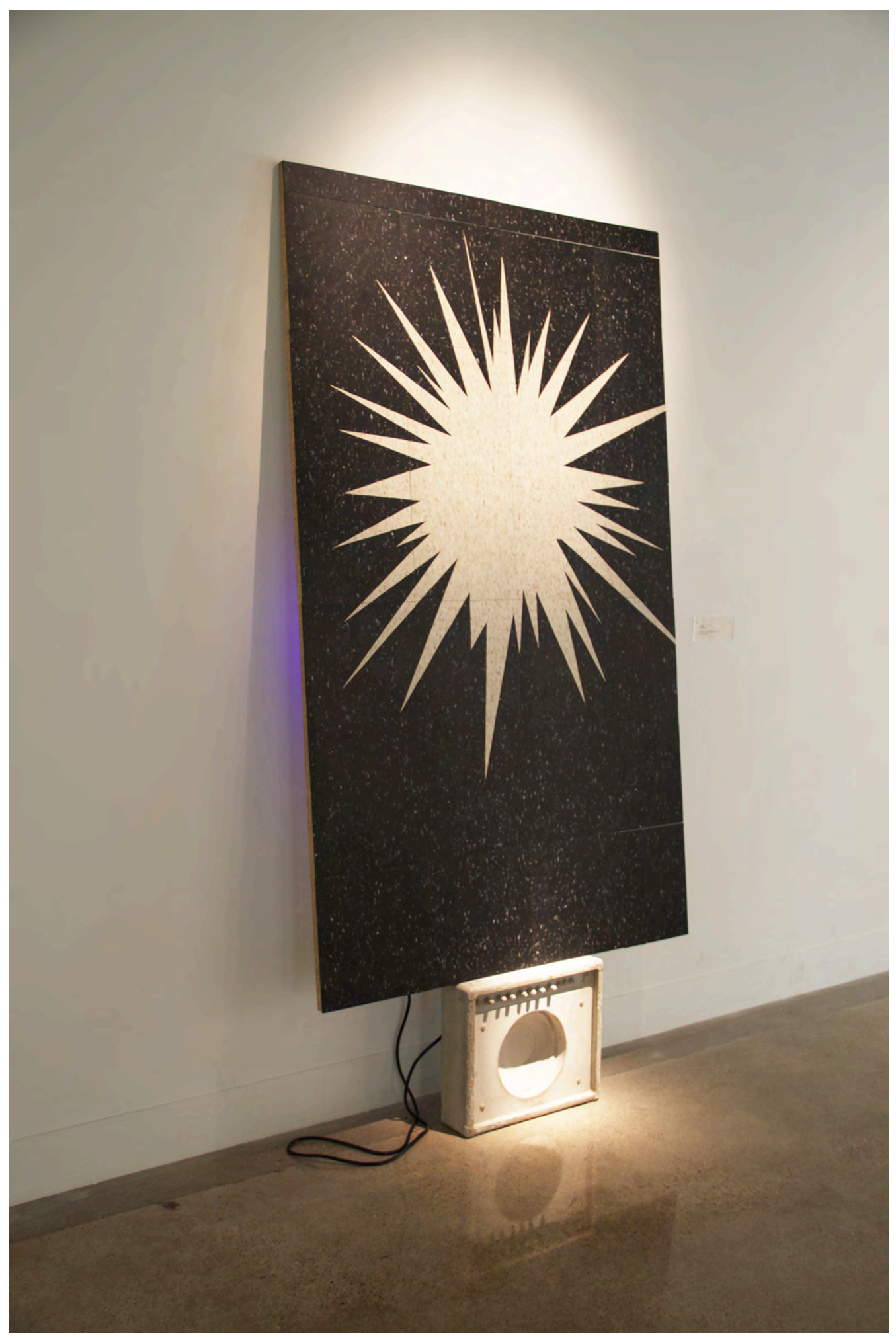

Figure 12: Exploded Floor, 2011 


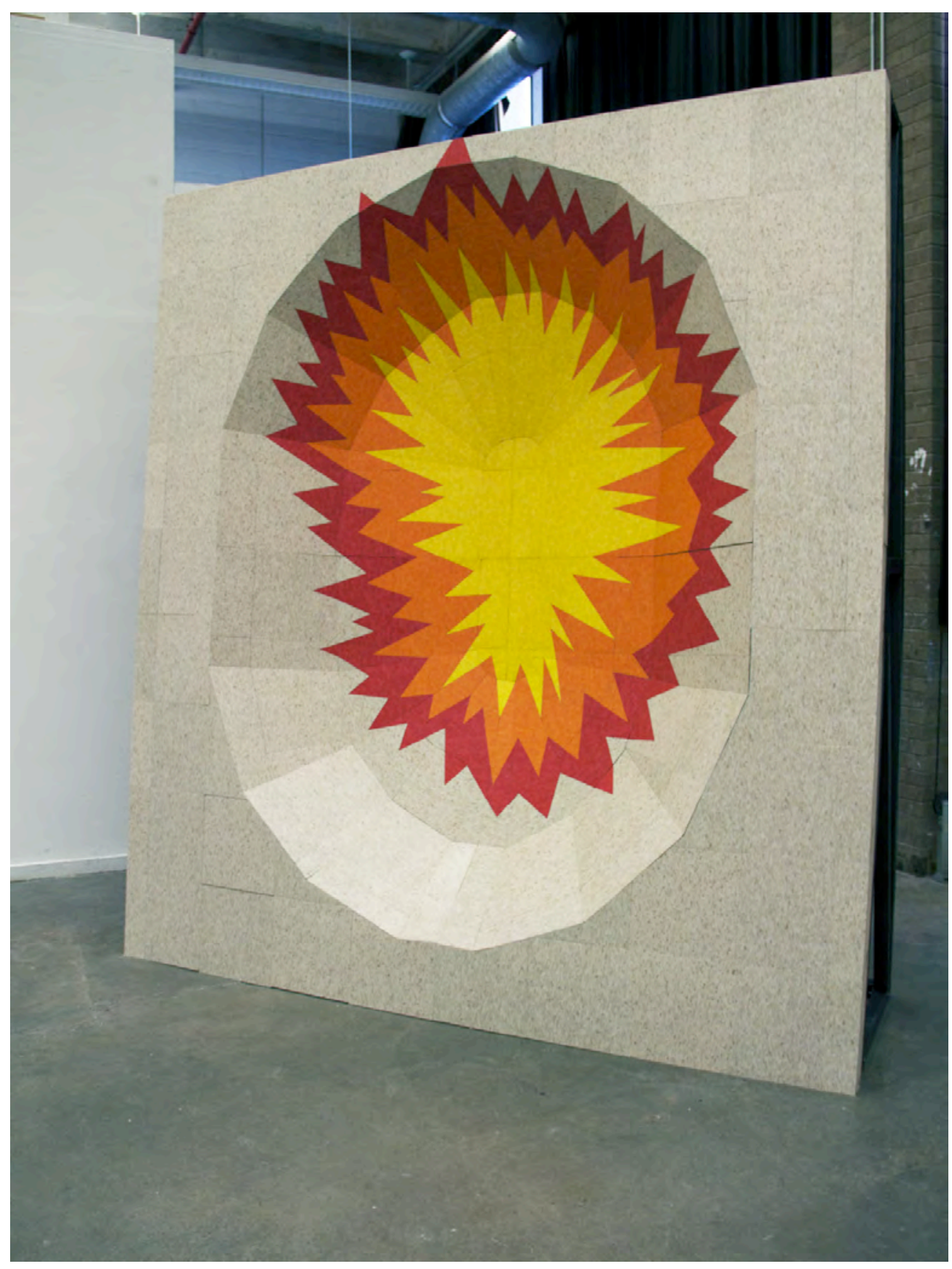

Figure 13: Exploded Floor II, 2011 
wanted to represent the destructive capabilities that we harness. By expressing the explosion through the intricate process of inlaying tile, I am proposing that our culture must be committed to our atomic reality.

In the most recent piece I have made, I encased a speaker and a microphone within a cube of concrete. The sound of a feedback loop is audible but muffled coming from the seemingly lifeless block, an apparently broken chunk from a collapsed concrete structure. As the most recent example of a piece that resonates with an action and a history, the surface texture of this piece, titled The Circular Ruins, 2011 (Figure 14), is cast from another historical object to suggest a deeper life contained within objects. The texture comes from one of five large (five to eight-ton) chunks of Pink Texas Granite that are lying seemingly immobile next to a railroad track in Austin. These large stones fell off a train en route to build the jetty for the shipping canal in Houston, which was built in 1890. For more than 120 years, these stones, foreign to this place, have been slowly settling into the ground. With each year, their journey is more dramatic.

In The Circular Ruins, each side of a concrete cube has an input for a cord, which both lead to an amp, creating a circular path through the block. The feedback loop creates both a sound and a vibration in the block, giving the concrete a hidden mystical power, although it looks like a defunct foundation pier. With this latest piece, I am becoming more interested in performing specific actions 


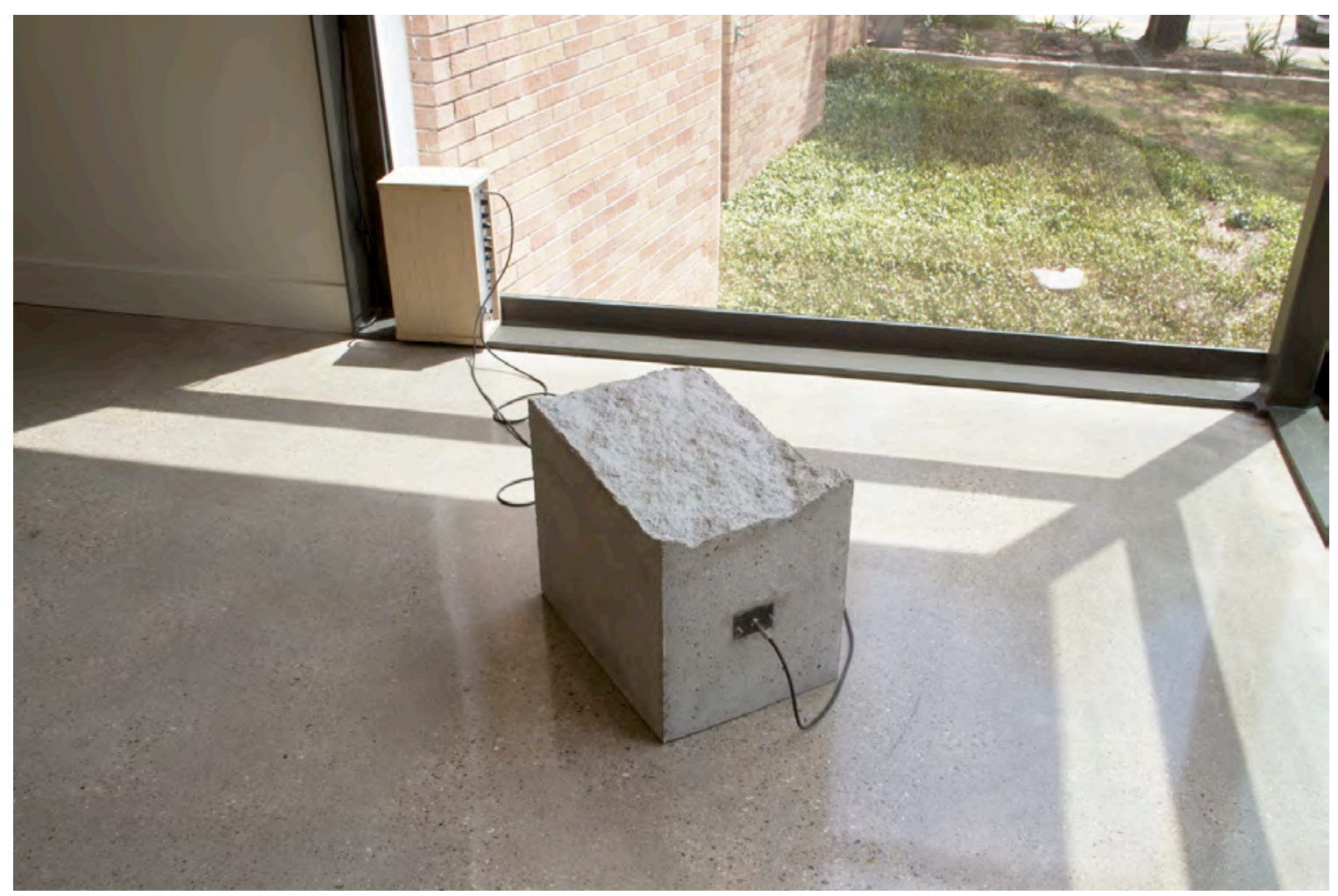

Figure 14: The Circular Ruins, 2011

toward materials that relate to architecture. Although I am interested in recreating objects through fabrication, I find my working philosophy follows that of Gordon Matta-Clark, by reactivating historic structures, and by using the art gallery as a space of investigation and questioning the ways that we see things and the ways in which objects are connected.

In The Circular Ruins, Jorge Luis Borges, the main character in the story devotes his time to dreaming a man into existence and teaching this man the ways of the world. In the last line of the story we discover that the dreaming man is also a dream. The history of objects is like this. Every object of our material culture is brought into being upon the backs of the objects that came before, and carries with it the experiences of our culture. Our buildings and ruins resonate 
with the ideals that created them and the conflicts that they encounter as history unfolds. 


\section{Bibliography}

Borges, Jorge Luis. "The Circular Ruins", translated by Anthony Bonner. From Ficciones. Grove Press, 1962. p.62.

Coates, Norma, "If Anything Blame Woodstock" in Performance and Popular Music, Edited by lan Inglis. Ashgate, Hampshire, England. 2006. P.58-69

Walker, Steven, Gordon Matta-Clark: Art, Architecture and the Attack on Modernism, I.B.Taurus, London, 2009, p.17 